\title{
COMENTÁRIO À TRADUÇÃO PARA O ESPANHOL DE TRÊS CONTOS DE NOITE NA TAVERNA, DE ÁLVARES DE AZEVEDO
}

\author{
A COMMENTARY ON THE TRANSLATION INTO SPANISH OF \\ THREE SHORTS STORIES FROM ÁLVARES DE AZEVEDO'S \\ NOITE NA TAVERNA
}

\author{
Andréa Cesco* Mara Gonzalez Bezerra**

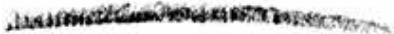

\section{RESUMO}

Noite na Taverna, de Álvares de Azevedo (1831-1852), está dividida em sete contos, sendo que o primeiro e o último funcionam como prólogo e epílogo. Os demais são narrados por cinco rapazes que dão nome aos contos. As misteriosas histórias, envolvendo amor e morte, são tétricas e trágicas. A obra, que é classificada como narrativa fantástico/gótica, e que ainda não possui publicação integral na língua espanhola, dispõe da tradução (realizada por nós) de três de seus contos - "Solfieri", "Gennaro" e "Último Beijo de Amor" - publicados em revistas acadêmicas. Neste artigo comentamos, através de alguns excertos, como foi traduzir no par contrário, do português ao espanhol - dando o devido cuidado à circulação sociocultural entre as línguas - alguns aspectos estilísticos e culturais relativos ao século XIX, encontrados contos e que nos levaram a uma reflexão sobre as escolhas. Para alcançar esses objetivos, buscamos nos apoiar, principalmente, em Even-Zohar, Berman e Peter Burke.

Palavras-chave: Noite na Taverna; tradução cultural; língua espanhola.

\section{ABSTRACT}

Noite na taverna, by Álvares de Azevedo (1831-1852), is divided into seven short stories, the first and the last working as prologue and epilogue. The others are narrated by five boys who give names to the tales. The mysterious stories, involving love and death, are tetrical and tragic. The work, which is classified as a fantastic/gothic narrative, and which has not yet been published in its entirety in the Spanish language, has the translation (our translation) of three of his short stories - "Solfieri", "Gennaro" and "Ultimo Beijo de Amor" - published in academic journals. In this article, we comment, through some excerpts, as it was translated in the opposite pair, from Portuguese to Spanish - giving due care to the socio-cultural circulation between languages - some stylistic and cultural aspects related to the 19th century, found tales that led us to a reflection on the choices. To achieve these goals, we sought to rely mainly on Even-Zohar, Berman and Peter Burke.

Keywords: A Night in the Tavern; cultural translation; Spanish language.

*Professora Associada do Programa de Pós-Graduação em Estudos Estudos da Tradução (PGET) e do Departamento de Língua e Literatura Estrangeiras da Universidade Federal de Santa Catarina. E-mail: andrea.cesco@gmail.com. "o presente trabalho foi realizado com apoio da Coordenação de

Aperfeiçoamento de Pessoal de Nível Superior - Brasil (Capes) - Código de Financiamento 001". Orcid: 0000-0002-4708-186X

**Professora do Curso de Letras Espanhol/UNIASSELVI e professora substituta no Departamento de Metodologia do Ensino/UFSC. Tradutora. E-mail: mara.gonzalez.letras@gmail.com. Orcid: 0000-0001-8390-5910 


\section{INTRODUÇÃO}

Noite na Taverna ([1855] 1988), livro de contos trágicos, nos quais o real e o extraordinário se entrelaçam criando uma sinistra e misteriosa atmosfera, reúne narrativas macabras contadas em um bar por cinco rapazes. Cada um, por sua vez, ganha a palavra para contar a sua história: "Solfieri", "Bertram", "Gennaro", "Claudius Hermann", "Johann". E a estas se juntam mais duas histórias: "Uma noite do século", que apresenta o ambiente e os personagens principais (funciona como um prólogo) e "Último Beijo de Amor", que abarca o desfecho da obra (o epílogo).

No que se refere às traduções das obras de Álvares de Azevedo, em uma rápida pesquisa no Index Translationum, da Unesco, e no catálogo de algumas bibliotecas nacionais, como Brasil, Argentina, Espanha, Estados Unidos e Reino Unido, nenhuma obra traduzida foi encontrada. No entanto, em uma busca pelo WorldCat, que mencionamos mais adiante, alguns registros foram encontrados. Assim, neste artigo comentamos, através de alguns excertos, como foi traduzir no par contrário, do português ao espanhol - dando o devido cuidado à circulação sociocultural entre as línguas - alguns aspectos estilísticos e culturais relativos ao século XIX, encontrados em três contos de Noite na taverna ("Solfieri", "Gennaro" e "Último Beijo de Amor") e que nos levaram a uma reflexão sobre as escolhas.

\section{A OBRA DE ÁLVARES DE AZEVEDO: NOITE NA TAVERNA}

No que diz respeito à obra do escritor, segundo a Academia Brasileira de Letras (ver nota 2), entre 1848 e 1851 Azevedo publicou alguns poemas, artigos e discursos. Depois surgem as Poesias (1853 e 1855), acrescidos de outros escritos. As Obras completas compreendem: Lira dos vinte anos, Poesias diversas, $O$ poema do frade e $O$ Conde Lopo (poemas narrativos); Macário; Noite na taverna; a terceira parte do romance O livro de Fra Gondicário; os estudos críticos sobre literatura e civilização em Portugal, Lucano, George Sand, Jacques Rolla, além de artigos, discursos e 69 cartas. A Lira dos vinte anos é a única obra de Azevedo cuja edição foi preparada pelo poeta. Vários poemas foram acrescentados depois da primeira edição, póstuma, à medida que iam sendo descobertos.

Noite na Taverna (1988) trata, conforme já mencionado, de uma antologia de sete contos fúnebres e aterradores. Cada conto está dentro de uma história maior. Fora o primeiro e o último, os demais são narrados por rapazes, protagonistas, cujos nomes dão título aos contos. Alves (1998, p. 127) diz que Azevedo volta a "representação literária para a expressão dos aspectos mórbidos da vida, ou melhor, a sua decisão de adotar o byronismo como uma tendência legítima para a literatura brasileira em oposição ao nacionalismo literário vigente."

Antonio Candido afirma que de todo o Romantismo brasileiro o escritor foi, por excelência, o poeta da noite, do sono e do sonho. "Na sua obra as amadas são vistas dormindo, o autor do enunciado também dorme com freqüência, ou sonha, ou se debate com a insônia. [...] $A$ noite na taverna se passa à noite, com personagens transitando a cada instante entre sono e vigília [...]" (CANDIDO, 1984, p. 46). E mais adiante o crítico vai concluir dizendo que "para ele [Âlvares de Azevedo] sono e sonho são estados favoráveis à expressão, inclusive porque dão acesso a certo tipo de espaço, o mais adequado à visão convulsa do Romantismo fantástico e macabro" (CANDIDO, 1984, p. 46).

Assim, no primeiro conto, o narrador apresenta o ambiente noturno, nebuloso e ébrio da taverna e das personagens, reunidas ali para beber e contar suas aventureiras e aterradoras histórias. "A mulher, o demônio, o amor, a morte ressurgem em cada conto na imaginação de Azevedo. Um ficcionista, adolescente, que associou o poeta imaginativo que era, ao ficcionista, em proveito do reino fantástico de Noite na Taverna" (RAMOS, 2006, p. 98).

No entanto, aqui fazemos um aparte com relação ao termo "fantástico", mencionado tanto por Candido quanto por Ramos. Miraglia (2013) afirma, nesses dois fragmentos, com relação à obra Noite da taverna que

Com base nas classificações actuais, que são resultado do trabalho crítico das últimas décadas do século XX, mas também reflexo da consciência literária da época, 
podemos enquadrá-la, com maior rigor, no gótico, em particular naquela sua vertente que procura de forma deliberada o efeito do horror, [...]

De todos os modos, sem entrarmos agora em complexas questões de classificação, podemos observar que fantástico, gótico e frenético, enquanto modos ou géneros, no sistema literário oitocentista, opõem-se ao realismo, ou para ser mais rigorosos ao mimético [...] (2013, p. 73-74).

Aliás, é importante mencionar que "Antonio Candido dedicou parte de seus estudos a Álvares de Azevedo, contribuindo para uma visada crítica que associa o poeta a um despontar de modernidade e a uma prodigalidade considerável." (ANDRADE, 2011, p. 55). Mais adiante Cândido vai falar exatamente do frenético.

Mas além disso elas [as narrativas] se ligam por certa comunidade de atmosfera, que as torna aspectos de uma linha ideal de assombramento e catástrofe. Estamos sem dúvida ante um produto do romance negro, mais particularmente da modalidade que os franceses chamam de "frenético" (1989, p. 16).

A partir daqui, vamos nos deter apenas nas histórias dos contos que, até o momento, foram traduzidos e publicados por nós: "Solfieri", "Gennaro" e "Último Beijo de Amor". Quanto ao primeiro, Solfieri relata a sua história de amor, funesto e de certa forma platônico, com uma mulher cataléptica que conheceu em Roma, "cidade do fanatismo e da perdição", quando a seguiu até um cemitério e ali esta desapareceu. Torna a vê-la, depois de um ano atordoado por essa lembrança, e após uma prolongada orgia, dentro de um caixão semiaberto, como morta. Após abraçá-la e ter com ela relações sexuais (revelando-se um necrófilo), ela desperta. Depois de dois dias juntos, de total êxtase, ela de fato morre. Solfieri guarda em seu quarto uma estátua da presunta mulher e, mantém junto ao peito, uma grinalda de flores.

Na próxima história, Gennaro, aprendiz do pintor Godofredo - que era pai da jovem Laura (de 15 anos) e casado pela segunda vez com Nauza (20 anos) -, seduz e engravida a primeira e posteriormente se apaixona pela segunda, que passa a ser sua amante. Laura, desiludida por Gennaro não querer se casar com ela, adoece e morre - ela e o filho no ventre -, mas não sem antes dizer que o perdoava e que assumia o próprio erro. Godofredo, uma noite, sai com Gennaro e, revelando saber de tudo (da filha e da esposa), tenta matá-lo com um punhal e este cai em um penhasco. Gennaro, preso a uma árvore, é socorrido e acorda na casa de camponeses. Recupera-se e volta à casa de Godofredo, munido do punhal que acabou encontrando no caminho. No entanto, lá encontra Nauza, morta por envenenamento pelo marido, e este morto também, com a boca espumando. Segundo Ramos,

Todos [os homens dos contos] perseguidos pela memória. Carregavam uma sina que invadia as trevas da morte, do demônio que agredia e perturbava o amor. Eles se embriagavam e tinham uma história maldita, Eros não se salvou. Tudo se estabelecia em função da morte (2006, p. 98).

O último conto/epílogo, "Último Beijo de Amor", que faz o fechamento da sequência de contos e onde se dá o trágico desfecho, está atrelado à história do conto anterior, em que o protagonista é Johann. Tarde da noite, quando todos já dormiam embriagados sobre as mesas da taverna, entra uma mulher vestida de preto, procura por alguém. Encontra Johann e corta-lhe a garganta. E vendo que Artur, que dizia ser Arnold, também ali estava, revela-se a ele, após transcorridos cinco anos sem se verem. Geórgia, que veio disposta a se vingar do irmão e pôr fím a própria vida, conta que a desonra no passado, causada pelo irmão, levou-a a se prostituir. Ambos se abraçam e se beijam e a história termina.

Para fechar esse tópico, no que se refere às questões mais estilísticas, de certa forma já apontadas anteriormente, aqui destacamos, nas palavras de Andrade (2011), que Noite na taverna

traz uma sequência de histórias que têm em comum o ambiente lúgubre, o mistério, uma dosagem intensa de satanismo e de soturnidade, e a presença do sobrenatural. Os 
personagens que contam as histórias estão embriagados, libertos de qualquer coerção, e o ambiente descrito é o de uma orgia permeada por penumbra e formas vagas. Entre vícios e crimes, os contos atingem os limites do êxtase e do pathos amoroso (ANDRADE, 2011, p. 154)

As narrativas ambientadas em cidades europeias remetem a temas próprios do romantismo, que fez escola no Brasil, e Álvares de Azevedo, leitor de Goethe e Byron, apresenta as características do estilo alemão e inglês. Cada conto é marcado pela tragédia, onde as mulheres, em sua maioria, são ingênuas ou prostitutas, assassinas, amantes, adúlteras, e os homens rendidos à luxuria e à devassidão. A natureza humana dos personagens sobressai e as intenções movidas pela paixão são mostradas sem pudor para um espectador voyeur.

\title{
3 TRADUÇÃO DA OBRA LITERÁRIA DE ÁLVARES DE AZEVEDO
}

Conforme mencionado na introdução, e sem obter sucesso, foram realizadas pesquisas para verificar que obras do escritor já haviam sido traduzidas para outras línguas no Index Translationum, da Unesco, e nos catálogos das bibliotecas nacionais do Brasil, Argentina, Espanha, Estados Unidos e Reino Unido. No entanto, em uma busca pelo WorldCat (um catálogo on-line gerido pelo Online Computer Library Center e considerado o maior catálogo on-line do mundo, albergando dados, registros e fichas de mais de 71.000 bibliotecas públicas e privadas de todo mundo), foram encontrados os seguintes registros:

Figura 1: WorldCat - Álvares de Azevedo

\author{
Macario $=$ 馬卡里奥 1 \\ Macario = Ma ka li ao \\ Autor: Alvares de Azevedo; Jingxin Xu; Fei Yan \\ $\square$ Libro impreso Ver todos los formatos e idiomas \\ Idioma: Portugués (por) \\ Editorial: 中之書, Macau : Zhong zhi shu, 2018. \\ Ediciones y formatos $x$
}

\author{
The Oxford book of Latin American poetry: a bilingual anthology. \\ Autor: Cecilia Vicuña; Ernesto Livon-Grosman; \\ $\square$ Libro impreso: Poesía Ver todos los formatos e idiomas » \\ Idioma: Inglés (eng) \\ Editorial: New York : Oxford University Press, 2009. \\ Ediciones y formatos $w$
}

\section{Anthologie de la poésie romantique brésilienne \\ Autor: Izabel Patriota P Carneiro; Didier Lamaison; \\ Libro impreso: Poesía Ver todos los formatos e idiomas w \\ Idioma: Francés (fre) \\ Editorial: Paris : Unesco : E. Carvalho, 2002.}

Ediciones y formatos " 
Fonte: Elaboração própria.

A primeira obra, Macário (peça teatral de 1852, que denuncia questões sociais), é uma tradução para o chinês, de Jingxin Xu e Fei Yan, publicada em 2018 e com 165 páginas.

A segunda, que se refere a uma antologia bilíngue de poesia latino-americana, de 2009, tem 561 páginas (há uma lista de 11 páginas dos tradutores que participaram da obra). Ela traz um compilado de poemas (alguns são apenas excertos) em português ou espanhol, com traduções para o inglês, de autores como Gregório de Matos, Sor Juana I. de la Cruz, Sousândrade, José J. Tablada, José M. Eguren, Olavo Bilac, Álvares de Azevedo, entre tantos outros. No caso deste último, foi traduzido um excerto de "Ideias Íntimas" ("Intimate ideas").

Quanto à terceira, Anthologie de la poesie romantique bresilienne, de 2002, tem 242 páginas. Trata-se de uma edição bilíngue: português e francês, de Izabel Patriota P. Carneiro e Didier Lamaison. A antologia apresenta poesias dos seguintes escritores: Gonçalves Dias, Álvares de Azevedo, Casimiro de Abreu, Fagundes Varela e Castro Alves. Para cada um deles há uma apresentação e uma seleção de poemas. No caso de Azevedo, temos: "Souvenir de mort" ("Memória da morte"), "Si je mourais demain!" ("Se eu morresse amanhã!"), "Sonnet" ("Soneto") e "Mon rêve" ("Meu sonho").

Com base nesta pesquisa realizada, verificou-se a acanhada publicação das obras de Azevedo para outras línguas. Em prosa, apenas Macário (a obra inteira) foi traduzida recentemente, em 2018, ao chinês. No que se refere a sua poesia, somente alguns poemas foram traduzidos e publicados em antologias: para o inglês temos um excerto, em 2009, e para o francês temos quatro poemas, em 2002. É no mínimo inusitado perceber que não apareçam traduções de Noite na taverna para outras línguas, apesar desta ter sido considerada a obra de maior êxito editorial do autor; "contam-se bem 9 edições até às primeiras décadas do século XIX, sem considerar as integradas nas Obras, e, facto curioso e notável, o romance acabou até por entrar no circuito da literatura popular" (MIRAGLIA, 2013, p. 67).

Dessa forma, gostaríamos de somar às traduções mencionadas as que realizamos para o espanhol de três contos de Noite na taverna: "Gennaro" e "Solfieri", publicados em 2013: o $1^{0}$ na Rónai, Revista de Estudos Clássicos e Tradutórios3 (vinculada ao Bacharelado em Tradução da Faculdade de Letras da UFJF), e o $2^{0}$ na Revista In-Traduções ${ }^{4}$ (vinculada ao Programa de Pós-Graduação em estudos de Tradução da UFSC). "Último beijo de amor"5 foi publicado em 2015, na Belas Infiéis, Revista do Programa de Pós-Graduação em Estudos da Tradução da UnB. Quanto aos demais contos que compõem essa obra, estes estão, no momento, em processo de tradução. Pretendemos, na sequência, publicar a obra toda.

\section{REFLEXÕES SOBRE O FAZER TRADUTÓRIO}

Nesta seção buscamos mostrar como se deram as reflexões que resultaram nas possíveis escolhas de tradução - no par português-espanhol - através de alguns excertos (vocábulos destacados em negrito e posteriormente comentados) retirados dos três contos publicados: "Solfieri", "Gennaro" e "Último Beijo de Amor". Na coluna da esquerda apresentamos o texto de partida, em português, e na da direita o texto de chegada, em espanhol. Enfatizamos que, devido à proximidade entre as duas línguas, procurou-se dar toda a atenção às possíveis interferências e ao mesmo tempo não descuidar dos aspectos estilísticos e culturais relativos ao autor e ao século XIX.

\section{1 "SOLFIERI"}

O conto inicia com Solfieri aludindo a Roma, onde se passa a trama, como lugar do fanatismo e da perdição, confrontando hipocrisia religiosa e devassidão. Ou seja, ali se apresenta o lugar propício para a história que se desenrola. E, na sequência, da assertiva se elucida a que esta se refere: "na alcova do sacerdote dorme a gosto a amásia", e "no leito da vendida se pendura o Crucifixo lívido". 


\begin{tabular}{|c|c|}
\hline $\begin{array}{l}\text { - Sabei-lo. Roma é a cidade do fanatismo e da } \\
\text { perdição: na alcova do sacerdote dorme a gosto a } \\
\text { amásia, no leito da vendida se pendura o Crucifixo } \\
\text { lívido. É um requintar de gozo blasfemo que mescla o } \\
\text { sacrilégio à convulsão do amor, o beijo lascivo à } \\
\text { embriaguez da crença! } \\
\text { (AZEVEDO, 1988) }\end{array}$ & $\begin{array}{l}\text { - Lo sabéis. Roma es la ciudad del fanatismo y de la } \\
\text { perdición: en la alcoba del sacerdote duerme a gusto } \\
\text { la amasia, en el lecho de la vendida se cuelga el } \\
\text { Crucifijo lívido. ¡Es un requintar de goce blasfemo } \\
\text { que mezcla el sacrilegio con la convulsión del amor, } \\
\text { el beso lascivo con la embriaguez de la creencia! } \\
\text { (AZEVEDO, } 2013 \text {, p. } 127 \text { ) }\end{array}$ \\
\hline
\end{tabular}

$\mathrm{Na}$ tradução, buscou-se manter o termo "alcova"/alcoba, que "de origem árabe, al-kobba significa esconderijo (MÉRITO, 1957), local onde se busca segurança", que no séc. XIX, "era o quarto dos prazeres, um espaço muitas vezes sem ventilação, nem iluminação: o ambiente mais privado da casa".6 Moreira (2018, p. 99) comenta que "la idea de espacio doméstico privado, íntimo y secreto cristalizará en una habitación particular: la alcoba". Michelle Perrot, em Historia de las alcobas $(2009, \mathrm{~s} / \mathrm{p})$, menciona que a literatura, por sua vez, embeleza-a com todas as cores possíveis [...]. Desconfia-se das estratégias de "câmara", como o fazem os galãs das jovens que estão sempre "em sua alcova".

No entanto, o autor, como forma de denúncia à vida "reclusa" dos sacerdotes que vivem em Roma - sede da Igreja Católica -, refere-se à alcova dos sacerdotes, onde a amásia (la amasia) "dorme a gosto", à vontade, sem nenhuma cerimônia, demonstrando ser este um ato corriqueiro na vida do sacerdote. Em espanhol: duerme a gusto ("según conviene, agrada o es necesario")7. Sendo que "no leito da vendida se pendura o Crucifixo lívido". Depois termina comentando que "É um requintar de gozo blasfemo que mescla o sacrilégio à convulsão do amor, o beijo lascivo à embriaguez da crença!". É o absoluto deleite e o completo ultraje ao sagrado, mesclando o libidinoso à descabida profanação do religioso. Quando Azevedo faz alusões diretas à simbologia cristã e ao centro do poder cristão, nos relembra o que Burke relata sobre insubordinações a partir do uso da língua: "Quando um veneziano educado do século XVII emprega o dialeto vêneto para escrever uma sátira política anônima, ele está sugerindo que o povo comum não está satisfeito com a política do governo e deixa ao leitor que decida se está querendo dizer algo mais" (BURKE, 2010, p. 60).

No segundo fragmento, Solfieri narra como possuiu a moça que estava sendo velada praticando a necrofilia (neste momento desconhece tratar-se de catalepsia). Pergunta-se, em uma combinação de excitação e desatino, se é "o anjo do cemitério", que ele havia seguido. Ou seja, não tem exata certeza de quem é. Ramos (2006, pp. 98-99) afirma que "os protagonistas das histórias de Azevedo se debatem no sofrimento, por um lado, ao mesmo tempo buscam o prazer insaciável, revestido na morte para dominar a angústia [...]".

\section{Quadro 2}

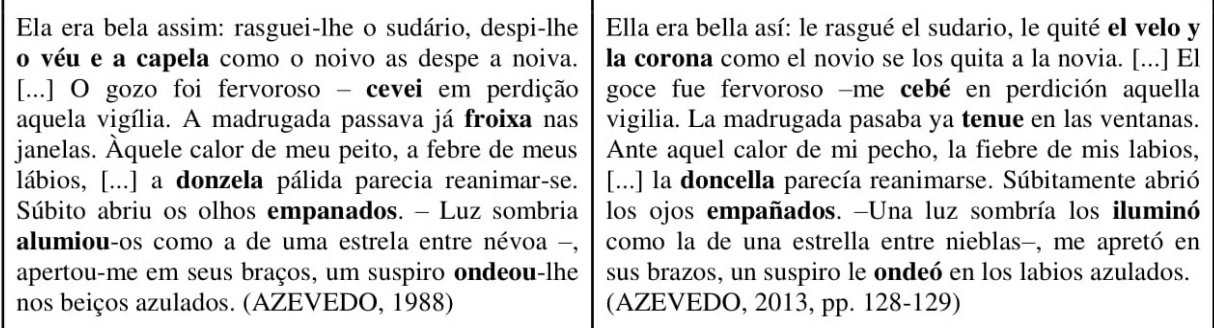

Ella era bella así: le rasgué el sudario, le quité el velo y la corona como el novio se los quita a la novia. [...] El goce fue fervoroso - me cebé en perdición aquella vigilia. La madrugada pasaba ya tenue en las ventanas. Ante aquel calor de mi pecho, la fiebre de mis labios, [...] la doncella parecía reanimarse. Súbitamente abrió los ojos empañados. -Una luz sombría los iluminó como la de una estrella entre nieblas-, me apretó en sus brazos, un suspiro le ondeó en los labios azulados. (AZEVEDO, 2013, pp. 128-129)

Nas primeiras três linhas da descrição, devemos levar em conta que não se trata realmente de uma "noiva", como Solfieri dá a entender, mas de uma morta. Então, no caso de "capela", que entre várias acepções temos a "coroa de flores; grinalda"8, em espanhol, descartamos o uso de guirnalda (usual em noivas) e decidimos por corona que tem um duplo uso: pode ser a da funerária como o "aro de ramas, flores, metal generalmente precioso, que se coloca en la cabeza como premio, adorno o símbolo de dignidad". 9

Traduzir implica em aquisição de compreensão leitora para entender as metáforas e as entrelinhas do texto, e a importância de ser um pesquisador e de ter outros saberes. Berman, 
quando discute isso, afirma que:

Experiencia de las obras y del ser-obra, de las lenguas y del ser-lengua. Experiencia, al mismo tiempo, de ella misma, de su esencia. En otros términos, en el acto de traducir está presente un cierto saber, un saber sui generis. La traducción no es ni una subliteratura (como creyó el siglo XVI) ni una subcrítica (como creyó el siglo XIX). Tampoco es una lingüística o una poética aplicadas (como se cree en el siglo XX). La traducción es sujeto y objeto de un saber propio. (BERMAN, 2014, p. 17).

$\mathrm{Na}$ sequência - o que vem a ser uma mescla de amor com profanação satânica - para demonstrar a intensidade do ato, temos o comentário debochado e atrevido do protagonista, já que estava em uma igreja: "O gozo foi fervoroso - cevei em perdição aquela vigília". O verbo "cebar", no Novo diccionario critico e etymologico da Lingua Portugueza (CONSTANCIO, 1836, p. 248), possui várias acepções, entre elas: nutrir, engordar, excitar o apetite; gozar, deleitar-se. Sendo assim, podemos deduzir que ele se fartou e se deleitou, em condenação eterna e em imoralidade aquela vigília ("estado de quem vela, fica desperto à noite").10 Em espanhol o verbo cebar tem acepções semelhantes ao português. Por isso a mantivemos: alimentar, fomentar um afeto, paixão, entregar-se com intensidade a algo, entre outras.

Em Azevedo nos deparamos com vários vocábulos com uso próprio do século XIX, como "cevar", "capela", conforme já visto, entre outras ainda como: "froixa", "donzela", "empanar", "alumiar" e "ondear". Para "froixo", o dicionário (CONSTANCIO, 1836, p. 576), acusa ser um termo já antigo e em desuso, e indica ver "frouxo", que significa flácido, pouco intenso, suave. Assim, no espanhol usamos tenue, no sentido de delicado, sutil, vaporoso. Para donzela (doncella), o mesmo dicionário (CONSTANCIO, 1836, p. 431) se refere a uma mulher solteira e moça que servia a uma senhora nobre; vale também para mulher nobre ou de distinção, em idade de casar. No espanhol (1869, p. 290,1), doncella é a mulher virgem ou ainda a criada que acompanha de perto e serve a uma senhora.11 Quanto aos verbos "empanar"/empañar, "alumiar"/iluminar e "ondear"/ ondear temos para o $1^{0}$ (CONSTANCIO, 1836, p. 450): embaciar, tirar o brilho. Para o $2^{\circ}$ (CONSTANCIO, 1836, p. 61): iluminar, aclarar; brilhar. E para o $3^{0}$ (CONSTANCIO, 1836, p. 729): fazer ondas; fazer flutuar; mover-se em ondulações. Em espanhol, temos como resultado algo bastante próximo da língua de partida.

\section{2 "GENNARO"}

Esta história, assim como a anterior, também tem como pano de fundo a Itália. E ela inicia com o diálogo, intensamente cadenciado, entre Bertram e Gennaro. Este se lembra de uma de suas histórias, envolvendo o velho pintor, Godofredo Walsh, e duas mulheres. O protagonista era, naquele momento seu aprendiz e morava na casa do mestre.

Quadro 3

\begin{tabular}{|c|c|}
\hline $\begin{array}{l}\text { - Gennaro, dormes, ou embebes-te no sabor do } \\
\text { último trago do vinho, da última fumaça do teu } \\
\text { cachimbo? } \\
\text { - Não: quando contavas tua história, lembrava-me } \\
\text { uma folha da vida, folha seca e avermelhada como as } \\
\text { do outono e que o vento varreu. } \\
\text { (AZEVEDO, 1988) }\end{array}$ & $\begin{array}{l}\text { - Gennaro, ¿duermes o te embebes en el sabor del } \\
\text { último trago del vino, de la última bocanada de tu } \\
\text { pipa? } \\
\text { - No: cuando contabas tu historia, recordaba una } \\
\text { hoja de la vida, hoja seca y rojiza como las del } \\
\text { otoño, y que el viento barrió. } \\
\text { (AZEVEDO, } 2013 \text {, p. } 198 \text { ) }\end{array}$ \\
\hline
\end{tabular}

No português, temos um diálogo bem ritmado, manifestado por repetições - último/última - folha/folha - e aliterações bem marcadas em "b", "v" e "f". Ainda temos a metáfora no trecho: "uma folha da vida, folha seca e avermelhada como as do outono e que o vento varreu". É possível perceber ainda, neste fragmento, traços de pessimismo e de melancolia, além da ânsia pelo passado e pela morte.

Na tradução, conforme Even-Zohar, (2013b, p. 5), entendemos que a "literatura traduzida não se desconectará da literatura original", por isso procuramos preservar tais características. 
Assim, mantivemos as repetições de último/última e hoja/hoja. Para estes últimos vocábulos fomos beneficiados pela sonoridade da $2^{\mathrm{a}}$ sílaba, que forma um conjunto de sons com estas palavras: Ge nnaro/hoja/hoja/rojiza/barrió. O "g", quando acompanhado de "e", é gutural, parecido ao "r" do português. O mesmo acontece com o "j", acompanhado de "a" e "i". Em espanhol é o que chamamos de uma fricativa velar sorda. No caso de barrió - uma vibrante múltiple alveolar sonora -, esta reforça o som do conjunto. E com os vocábulos embebes/sabor/(b)vino/bocanada/contabas/ recordaba/(b)vida/(b)viento /barrió temos um conjunto de vocábulos ainda maior que interagem foneticamente, formando um grande grupo aliterativo. E isso porque o "v" é pronunciado em espanhol como a letra "b".

Neste segundo fragmento, que apresenta o momento final do conto, Gennaro descreve sórdida e friamente como encontrou Nauza (a amada) e seu marido, o pintor, ambos mortos por envenenamento (este a mata e depois se suicida). Nele encontramos aspectos macabros, horripilantes e, ao mesmo tempo, carregados de uma boa dose de asco, dada a narrativa de deterioração dos corpos. "A moda? Apreciar a beleza do horror, considerado uma fonte de sensações" (DEL PRIORI, 2019). Nota-se a total apatia e indiferença de Gennaro com relação à mulher amada; há somente a mera descrição de uma cena que, se supunha, deveria deixá-lo abalado, já que em outros momentos ele havia se declarado a ela: "Uma noite eu disse a Nauza que a amava: ajoelhei-me junto dela, beijei-lhe as mãos, reguei seu colo de lágrimas".

Quadro 4

\begin{tabular}{|l|l|}
\hline $\begin{array}{l}\text { Ergui os cabelos da mulher, levantei-lhe a cabeça. } \\
\text { Era Nauza, mas Nauza cadáver, já desbotada pela } \\
\text { podridão. Não era aquela estátua alvíssima de }\end{array}$ & $\begin{array}{l}\text { Erguí los cabellos de la mujer, levanté su cabeza. Era } \\
\text { Nauza, pero Nauza cadáver, ya empalidecida por la } \\
\text { putrefacción. No era aquella estatua albísima de } \\
\text { outrora, as faces macias e colo de neve. Era um } \\
\text { corpo amarelo... Levantei uma ponta da capa do } \\
\text { cuerpo amarillo... Levanté una punta de la capa del } \\
\text { outro - o corpo caiu de bruços com a cabeça para } \\
\text { baixo - ressoou no pavimento o estalo do crânio. } \\
\text { otro - el cuerpo cayó de bruces con la cabeza hacia } \\
\text { Era o velho - morto também e roxo e apodrecido: } \\
\text { eu o vi - da boca lhe corria uma escuma esverdeada. } \\
\text { (AZEVEDO, en el suelo el chasquido del cráneo. } \\
\text { Era el viejo - muerto también y morado y podrido: } \\
\text { yo lo vi - de la boca le chorreaba una espuma } \\
\text { verdosa. } \\
\text { (AZEVEDO, 2013, p. 205) }\end{array}$ \\
\hline
\end{tabular}

O que temos neste fragmento é uma descrição mórbida e sombria daquela que já não é a Nauza, e sim a Nauza "cadáver". E esta palavra não poderia ser traduzida de outra maneira - como defunta ou morta - porque no texto está muito mais para cadavérica e esquálida, que já está "desbotada pela podridão" (empalidecida por la putrefacción). Poderíamos ter escolhido podredumbre ou descomposición, mas não seriam tão fortes e alusivas quanto putrefacción, que tem o apelo do cheiro repugnante e está diretamente relacionada à morte. Assim, priorizamos a tradução ética em oposição à etnocêntrica, de acordo com a proposta de Berman (2013, p. 35). Na sequência, como um choque de contrários, a mulher que antes era "alvíssima", com "colo de neve" - explorando o branco como símbolo de beleza, pureza, fidelidade e ausência do pecado -, transforma-se no amarelo desbotado, cor assumida perto da morte. "Conforme expõem Pastoureau e Simonnet (2008 pp. 80-81), na Europa Medieval [...] o amarelo que não brilha nem ilumina como o ouro era tomado negativamente, tendo se tornado a cor do outono, do declínio, da doença, e também um símbolo de traição e mentira" (PEREIRA, 2011, p. 104). Ou seja, ironicamente, a mulher perfeita e inatingível destoa bruscamente com a morbidez, o sombrio e o abismo da morte. $\mathrm{Na}$ tradução, além das alusões ao branco, buscamos manter também uma aliteração em "a": "No era aquella estatua albísima de antaño, la faz suave y el pecho de nieve".

Na descrição do homem morto, um movimento de Gennaro faz com que o corpo deste caia de cabeça para baixo - o que já nos provoca uma apreensão visual, seguida da sensação bem desagradável da cabeça se partindo -, "[...] ressoou no pavimento o estalo (chasquido) do crânio". A mulher estava amarela e o homem está roxo (morado)12 e, também, apodrecido (podrido), remetendo à morbidez da mortificação. A cor também remete à morte e ao luto.

E para fechar a explicação do fragmento 4 (que encerra o conto), e sua tradução, temos como último aspecto da descrição o fato de que da boca do homem ainda "corria uma escuma esverdeada", sinal do suicídio por envenenamento, da bílis que pode ter uma tonalidade 
esverdeada: "de la boca le chorreaba una espuma verdosa".

\section{3 "ÚLTIMO BEIJO DE AMOR"}

Este conto, o último de Noite na Taverna, relata o fim de uma noitada, no bar, onde todos se encontram dormindo. Ele conta o encontro de dois amantes, após alguns anos, e a elucidação dos fatos que aconteceram desde a última vez que se viram e o fechamento de sua história amorosa, mas não sem antes estar permeada também pela morte. Nesse único fragmento que analisamos, é descrita a cena em que a moça, que havia sido seduzida pelo próprio irmão, retorna agora ao bar para matá-lo.

Quadro 5

\begin{tabular}{|c|c|}
\hline $\begin{array}{l}\text { baixou-se junto dele, de } \\
\text { Ime baço da lanterna } \\
\text { palhava sombra sobre Jo } \\
\text { endeu e sua mão passo } \\
\text { luço rouco e sufocado o } \\
\text { vantou-se. Tremia; e } \\
\text { sssoou-lhe na mão um } \\
\text { tirou-o ao chão. Viu qu }\end{array}$ & $\begin{array}{l}\text { mujer pe } \\
\text { Un sollc } \\
\text { desconoc } \\
\text { linterna } \\
\text { puñal... }\end{array}$ \\
\hline
\end{tabular}

Novamente temos a presença de um vocabulário próprio do século XIX, com "depôs a lâmpada"/"lume baço". "Depor" é um verbo muito mais usado atualmente para "testemunhar" e "destituir de cargo, função, posto".13 Mas, neste fragmento indica, segundo Constâncio (1836, p. 358), "pôr de parte, largar, deixar, apartar de si". Em espanhol, temos exatamente o mesmo sentido para deponer, termo por nós selecionado: "dejar, separar, apartar de si alguna cosa" (1852, p. 226,1).14 Quanto à "lume baço", o primeiro se refere à "luz, vela, cirio, tocha" (CONSTÂNCIO, 1836, p. 664), e o outro à "privado de lustre, sem lustre, que perdeu o brilho, como engordurado, empannado, turvo; moreno" (CONSTÂNCIO, 1836, p. 152); ou seja, "a luz turva da lanterna". Em espanhol optamos por "la lumbre mate de la linterna" - onde mate significa "amortiguado, apagado, sin brillo" (1899, p. 642,3)15 - para manter esse estranhamento no leitor, de termos historicamente distantes, e por conter uma sonoridade que embala esse conjunto de palavras.

Toda obra comporta um texto "subjacente", onde certos significantes chave se correspondem e se encadeiam, formam redes sob a "superfície" do texto, isto é: do texto manifesto, dado à simples leitura. É o subtexto que constitui uma das faces da rítmica e da significância da obra (BERMAN, 2013, pp. 78-79).

Na sequência, temos a descrição do assassinato cometido pela mulher. Nota-se que a fronte dela "pendeu" (pendió) e sua mão "passou" (pasó) na garganta dele, indicando completa sutileza na ação de cortar a garganta, como se fosse até de forma lenta, a ponto do leitor só se dar conta do ato no final do fragmento. Temos a impressão de que pode ter sido até por acaso, e que só depois ela percebe o que fez: "Tremia; e ao segurar na lanterna ressoou-lhe na mão um ferro... Era um punhal... Atirou-o ao chão". No entanto, após ela ver que suas mãos estão vermelhas, paradoxa e friamente, as enxuga "nos longos cabelos de Johann...", o defunto. Na tradução, procuramos reproduzir essa lentidão e as incertezas produzidas na narrativa, buscando gerar também indefinições no leitor.

\section{CONSIDERAÇÕES FINAIS}

Em Noite na Taverna é o álcool que motiva o entusiasmo e a contação de histórias, assim como a reunião e os seus excessos. A obra, que está dividida entre narradores e ouvintes de um bar, expõe as confissões noturnas de um grupo de rapazes. Um fantasma do passado ronda cada um 
deles, o que confere às histórias uma angústia palpável na voz narrativa, sobre os excessos e as faltas do passado, próprios de textos românticos.

Os narradores dos contos são todos homens, e as mulheres, ora assassinas, ora donzelas idealizadas, são vítimas de relações perversas e cruéis, onde o narrador parece estar ora em vantagem ora em desvantagem. Azevedo estabelece um paradoxo a cada narrativa e o perfil psicológico de cada um dos personagens demonstra uma preocupação em burilar cada personagem, conferindo à narrativa aspectos de verossimilhança.

Azevedo mantém uma distância narrativa ao escolher a taverna como o local para falar de temas incomuns à sociedade brasileira da época, e desta forma não chocar os seus leitores com os temas abordados nos contos. A embriaguez geral permite e justifica os excessos e exageros narrados. E embora Azevedo nunca tenha ido além de São Paulo ou do Rio de Janeiro, coloca a cidade de Roma como um de seus cenários míticos.

Assim, a nossa tradução dos contos teve como objetivo prezar a manutenção, na medida do possível, de aspectos estilísticos e culturais relativos ao século XIX, e manter o ambiente das narrativas, levando, dessa forma, o leitor a experimentar a sensação de adentrar em uma densa noite nebulosa e de trevas, onde a construção dos cenários e das personagens marcam o desenvolvimento da narrativa. "La lectura, la selección, la sustitución, establecen diálogos implícitos entre lenguas, entre normas y tradiciones" (PASERO, 2004, p. 96).

Even-Zohar sugere que para uma obra literária circular não depende apenas de variantes econômicas: "do ponto de vista do consumo, os 'textos' circulam no mercado de modos variados e nunca apenas - especialmente se estão altamente canonizados e armazenados afinal no cânone histórico - como os vêm os críticos literários, por exemplo, como textos integrais" (EVEN-ZOHAR, 2013a, p. 42). E a obra de Álvares de Azevedo, mesmo reconhecida no cânone de literatura brasileira, ainda não se encontra em um sistema literário de língua espanhola.

Nesse sentido, traduzir Álvares de Azevedo significa levar o seu texto a outra língua, promovendo assim a circulação literária entre diferentes culturas e, ao mesmo tempo, propicia aos leitores de língua espanhola a possibilidade de gerar uma tradução entre polissistemas. Nascimento e Barreiro comentam que:

A tradução de obras e autores brasileiros, principalmente da literatura, tornou possível o conhecimento do país e de suas regiões. Essa possibilidade conferiu às obras e a seus autores um caráter de representatividade de uma cultura, processo que ajudou a consolidá-los, dentro e fora dos limites do país, como representantes da literatura universal. (2016, p. 301)

Assim, ao considerar a tradução como um contato entre línguas, desde uma perspectiva ética, consideramos o ato de traduzir um exercício de relações onde se permita a circulação no sistema literário espanhol da literatura brasileira. "Bilingüe por definición, el traductor es, en efecto, sin discusión posible, el lugar de contacto entre dos (o varias) lenguas empleadas alternadamente por el mismo individuo [...]" (MOUNIN, 1971, p. 18).

\section{REFERÊNCIAS}

ALVES, Cilaine. O Belo e o Disforme: Álvares de Azevedo e a Ironia Romântica. São Paulo: Editora da USP/FAPESP, 1998.

ANDRADE, Alexandre de M. "A transcendência pela natureza em Álvares de Azevedo", tese de doutorado pela Pós-Graduação em Estudos Literários da Faculdade de Ciências e Letras UNESP/Araraquara. Orientador: Antônio Donizeti Pires. São Paulo. 2011.

AZEVEDO, Álvares de. Noite na taverna. 3.ed. Rio de Janeiro: Francisco Alves, 1988. Texto proveniente de: A Biblioteca Virtual do Estudante Brasileiro A Escola do Futuro da Universidade de São Paulo Permitido o uso apenas para fins educacionais.

AZEVEDO, Álvares de. II Solfieri, in In-Traduções. Florianópolis (SC), v. 5, n. 9, pp. 125-136, jul./dez. 2013. Tradução de Mara Gonzalez Bezerra e Andréa Cesco. https://periodicos.ufsc.br/index.php/intraducoes/article/view/62332 
AZEVEDO, Álvares de. IV Gennaro, in Rónai: Revista de Estudos Clássicos e tradutórios. Juiz de Fora (MG), v. 1, n. 2, pp. 198-206. 2013. Tradução de Mara Gonzalez Bezerra e Andréa Cesco. https://periodicos.ufjf.br/index.php/ronai/article/view/23084

AZEVEDO, Álvares de. Último beijo de amor, in Belas Infiéis, Revista da Pós-Graduação em Estudos da Tradução da UnB. Brasília, 4(1). 2015. Tradução de Mara Gonzalez Bezerra e Andréa Cesco. https://periodicos.unb.br/index.php/belasinfieis/article/view/11322

BERMAN, Antoine. La traducción y la letra o el albergue de lo lejano. 1a ed. Buenos Aires: Dedalus, 2014

BERMAN, Antoine. A tradução e a letra ou o albergue do longínquo. Tradução de Marie-Hélène C. Torres, Mauri Furlan, Andréia Guerini. 2. ed. Tubarão: Copiart; Florianópolis: PGET/UFSC, 2013.

BURKE, Peter. Cultura Popular na Idade Moderna. Europa, 1500-1800. Tradução de Denise Bottmann. São Paulo: Cia das Letras, 2010.

CANDIDO, Antonio. Na sala de aula. Caderno de análise literária. Série Fundamentos. São Paulo: Editora Ática, 1984.

CANDIDO, Antonio. A educação pela noite \& outros ensaios. São Paulo: Ática, 1989.

CONSTANCIO, Francisco Solano. Novo diccionario critico e etymologico da Lingua Portugueza. Angelo F. Carneiro (ed.). Paris: Officina Typographica de Casimir, 1836.

DEL PRIORI, M. Necrofilia e morte: os prazeres mórbidos na época do Romantismo, in Aventuras na Historia, 2019. Acesso 25/02/2020. Disponível em: encurtador.com.br/pqrw2.

EVEN-ZOHAR, Itamar. O Sistema Literário. Tradução de Luis F. Marozo e Yanna K. Cunha. Translatio.Revista do Núcleo de Est. de Tradução Olga Fedossejeva. Instituto de Letras da UFRGS. n. 5, 2013a. Disponível em https://seer.ufrgs.br/translatio/article/view/42900/27135. Acesso em $22 / 3 / 2020$

EVEN-ZOHAR, Itamar. Teoria dos Polissistemas. Tradução e Luis F. Marozo, Carlos Rizzon e Yanna K. Cunha. Translatio. Revista do Núcleo de Est. de Tradução Olga Fedossejeva. Instituto de Letras da UFRGS. n. 5, 2013b. Disponível em: https://seer.ufrgs.br/translatio/article/view/42899. Acesso em 22/3/2020.

MIRAGLIA, Gianluca. Entre a negridão da noite e a luz dourada na lâmpada, a Noite na Taverna de Álvares de Azevedo, in Rassegna Iberistica, n. 98, pp. 63-77, 2013.

MOREYRA, Cecilia. La alcoba, el lecho, lo cotidiano. Cultura material de un espacio doméstico. Córdoba (Argentina), siglos XVIII y XIX, in Páginas. Revista digital de la Escuela de Historia. Universidad Nacional de Rosario. Año 10, n. 24, 2018.

MOUNIN. Georges. Los problemas de la traducción. Madrid: Editorial Gredos, S.A 1971.

NASCIMENTO, Geovanio Silva do; BARREIROS, Patrício Nunes. O léxico regional na obra $O s$ Sertões e sua tradução para o espanhol, in TradTerm, São Paulo, v. 28, 2016.

PASERO, Carlos A. Los límites de la lengua. Benjamín de Garay y la praxis de la traducción, in Graphos, João Pessoa, v. 6, n. 2/1, 2004.

PEREIRA, Carla P. de A. A cor como espelho da sociedade e da cultura: um estudo do sistema cromático do design de embalagens de alimentos. Tese de doutorado FAUUSP. São Paulo, 2011. Disponível em: https://www.teses.usp.br/teses. Acesso em 25/02/2020.

PERROT, Michelle. Historia de las alcobas (Histoire de chambres). Traducción de Ernesto Junquera. Editor digital Turolero, 2009.

RAMOS, M.B.J. Psicanálise e literatura: Noite na Taverna. Estud. psicanal. Belo Horizonte, n. 29, p. 97-106, 2006. Disponível em encurtador.com.br/epMX8. Acesso em 18/02/2020.

WAQUIL, Marina Leivas. A noção de problema nos Estudos da Tradução: um novo olhar teórico com exemplos do par linguístico espanhol/português. Belas Infiéis, Brasília, v. 8, n. 4, p. 13-34, 2019. 


\section{NOTAS}

1 ÁlVARES de Azevedo. In: ENCICLOPÉDIA Itaú Cultural de Arte e Cultura Brasileiras. São Paulo: Itaú Cultural, 2020. Disponível em: . Acesso em: 13 de Fev. 2020. Verbete da Enciclopédia. ISBN: 978-85-7979-060-7

2 Academia Brasileira de Letras. Álvares de Azevedo. Disponível em: Acesso em 13 de Fev. 2020.

32 2013, v. 1, n. 2, pp. 198-206. https://periodicos.ufjf.br/index.php/ronai/article/view/23084/12758

4 2013, v. 5, n. 9, pp. 125-136. https://periodicos.ufsc.br/index.php/intraducoes/article/view/62332

5 2015, v. 4, n. 1, pp. 207-211. https://periodicos.unb.br/index.php/belasinfieis/article/view/11322/9960

6 Estilos Arquitetônicos Alcova (quarto) Estilos Arquitetônicos. Disponível em: https://www.estilosarquitetonicos.com.br/alcova-quarto/. Acesso em 23/02/2020.

7 Diccionario de la Real Academia Española. Disponível em: https://dle.rae.es/gusto?m=form. Acesso em $23 / 02 / 2020$

8 Dicionário Aulete Digital. Disponível em: http://www.aulete.com.br/capela. Acesso em 23/02/2020.

9 Wordreference. Diccionario de español. Disponível em: https://www.wordreference.com/definicion/corona. Acesso em 23/02/2020.

10 Dicionário Aulete Digital. Disponível em: http://www.aulete.com.br/vigilia. Acesso em 23/02/2020.

11 Nuevo Tesoro Lexicográfico de la Lengua Española. Disponível em: http://ntlle.rae.es/ntlle/SrvltGUIMenuNtlle?cmd=Lema\&sec=1.0.0.0.0. Acesso em 24/02/2020.

12 La expresión latina livor mortis se refiere al color morado que adquiere el cuerpo de una persona fallecida.

13 Dicionário Aulete Digital. Disponível em: http://www.aulete.com.br/depor. Acesso em 22/03/2020.

14 Nuevo Tesoro Lexicográfico de la Lengua Española. Disponível em: http://ntlle.rae.es/ntlle/SrvltGUIMenuNtlle?cmd=Lema\&sec=1.1.0.0.0. Acesso em 22/03/2020.

15 Nuevo Tesoro Lexicográfico de la Lengua Española. Disponível em: http://ntlle.rae.es/ntlle/SrvltGUIMenuNtlle?cmd=Lema\&sec=1.1.0.0.0. Acesso em 22/03/2020. 